\title{
Fostering Students Entrepreneurship through Digital Platforms
}

\author{
Nikollaq Pano, Ira Gjika* \\ Department of Economy, Faculty of Economic Sciences, Mediterranean University of Albania, Albania
}

Received March 30, 2020, Revised May 4, 2020, Accepted May 27, 2020

Copyright $(2020$ by authors, all rights reserved. Authors agree that this article remains permanently open access under the terms of the Creative Commons Attribution License 4.0 International License

\begin{abstract}
Entrepreneurship is a process characterized by the pursuit of opportunity. It is a series of steps that combines knowledge and skills to enable the process of value creation in fulfilling a market need. The role of education is increasing in successful entrepreneurial activities worldwide. Our work intends to contribute in highlighting and strengthening relations between university education and entrepreneurship in Albanian context. Following the European Directive "Rethinking Education Strategy" several Albanian universities are considering new methods for encouraging university ventures. One of the means suggested is through digital platforms established by and in universities that can play a significant role to push Albanian university education towards the closest collaboration with entrepreneurship and market. After the 'business incubators' wave, digital platforms are becoming the main stimulating tool of innovation and entrepreneurial spirit for young people, successfully used by many foreign universities. This study presents a new platform called Launchpad Albania, purposely designed to stimulate the development of new business ideas and to evaluate their success probability. Mainly intended for use by university students, it helps to find associates that support the business ideas and assist with business plan drawing. The expectations from this study are to facilitate establishment of digital platforms where universities, private businesses, banks, students, and lecturers are involved for entrepreneurial activities. This is the main theoretical and practical contribution to the benefit of Albanian universities in their efforts to encourage the entrepreneurial spirit, both at the individual and institutional level.
\end{abstract}

Keywords Entrepreneurship, Higher Education, Digital Platforms, Business Ecosystem

\section{Introduction}

Recent decades have seen an economic development accompanied by ups and downs within Europe, as well as globally. The important changes in the labor market [1], the unprecedented increase in youth unemployment rate [2], and the unification of labor market in the European Union [3] urged European institutions to seek stable development policies by paying particular attention to the expansion of entrepreneurial education (EE), especially at the university level, and by establishing a novel entrepreneurial ecosystem in all European universities. New methods and practices aiming to prompt the entrepreneurial spirit of the younger generation were tested and applied during instruction as well as in extracurricular activities. The American model, based on Silicon Valley's entrepreneurial ecosystem, as comprehensively described by Eesley and Miller [4], has been impressive. Consequently, it was necessary to consolidate these methods at the European level and support all new systems inciting youth entrepreneurship and innovation [5].

Significant changes accompanied this process in universities and other higher education institutions (HEIs). New courses on Entrepreneurship and Innovation were added to undergraduate and graduate programs; there was increased cooperation with banks in financing business ideas, and universities began receiving progressively more funds from the private market.

These changes eventually became evident in Albanian education, especially after the approval of the new law on higher education in 2015 [6]. The statement of Peter Drucker [7] that "entrepreneurship in society - and it is badly needed - requires above all application of the basic concepts, the basic techné, of management to new problems and new opportunities" became more than relevant to our education system and society as a whole. 
The experience of the authors in entrepreneurship education, the recognition of venture's situation in Albanian university environment, and the perception of current opportunities lead to the research work presented in this paper.

\section{Problem Statement and Objectives}

\subsection{Role of Entrepreneurship Education}

Entrepreneurship is the result of a combination of knowledge, skills, and a mindset that accompany a process of value creation providing goods and services to market needs [8]. Entrepreneurs are at the core of the process and their capabilities affect the results of their ventures. The knowledge and attitudes students acquire in universities will be reflected in their work. They will also facilitate the knowledge transfer, which is becoming a key issue in the economic agenda of international institutions [9].

Therefore, it is expected that universities play a central role in nurturing entrepreneurship through knowledge creation (entrepreneurship and management research) and knowledge dissemination (entrepreneurship education and training). In addition, leading universities provide hands-on support for young entrepreneurs and promote entrepreneurship culture, emphasizing their role and contribution, especially in the European environment $[3,9,10]$. We acknowledge worldwide experience and progress; however, the geographical position of our country aligns us mostly with the initiatives of European institutions and universities.

There is a vast literature dealing with entrepreneurship and innovation, as well as the role of education on them. Theoretical work of early scholars such as J. Schumpeter and P. Drucker has been followed by extensive analysis and case studies, generally emphasizing that entrepreneurship is a learning process, highly influenced by education [11]. With regards to creation of successful businesses in recent years, Ries [12] asserts that "entrepreneurship is management" and it goes through validated learning.

Research work of numerous authors attributes to entrepreneurship education (EE) in universities a significant role in business creation, growth, and employment. Lendner [5] provides evidence and highlights the role of instruments, like university incubators in business creation in the form of start-ups and start-up success stories are abundant [13]. Contribution of Universities Alliance [8] in creation and growth of new enterprises through research, education, and entrepreneurship support is expanded on different countries and industry sectors in the form of successful projects. Furthermore, surveys and studies from the UK [14], Italy, Denmark [10], USA [4], and other countries underline that entrepreneurship courses and programs encourage the entrepreneurial intentions of students [14]. Entrepreneurship education has a positive impact on students' ability to achieve objectives, build relationships, as well as on problem-solving abilities [15]. Students' competencies to exploit opportunities and develop business ideas are improved through education. Management skills developed through learning help students to plan and implement their business ideas effectively and efficiently. Curth et al. [16] emphasize that students participating in entrepreneurship education are more likely to start their own business and their companies tend to be more innovative and more successful than those led by persons without entrepreneurship education background. Furthermore, entrepreneurship education encourages self-employment in students, as well as development of their businesses. So, combining academic knowledge with practical work accordingly leads to higher incomes. Surveys show that "the more training and education, the higher the income the effects seem to accumulate" [16].

Moreover, the positive impact of entrepreneurship education goes beyond students and alumni. It extends to educational institutions, economy and society.

HEIs providing entrepreneurship education can develop a stronger entrepreneurial culture within the organization and a higher engagement of staff to support their students' entrepreneurial learning process.

The impact of EE on the economy is multifaceted: more companies established, increased number of successful ventures, more people employed, more revenues, and higher activity in innovative sectors [4,9,16]. HEIs promoting students' entrepreneurial capabilities may contribute to reduce skills mismatches in labor markets $[1,10]$, which is nowadays a concern for many countries.

The main, general contribution EE has in society is through knowledge exchange and collaboration, as universities establish connections within ecosystems. Beyond teaching and research, which are the two primary missions, the third mission of HEIs is defined as the stimulation, direct application, and exploitation of knowledge for the benefit of the social, cultural, and economic development of society $[10,17]$. In other words, the contribution of educational institutions in transferring knowledge to industry and encouraging innovation goes to the benefit of the entire society. However, there is also impact to society in real terms. Although limited, there is evidence in European countries that entrepreneurship education can contribute to social inclusion of young people [16].

\subsection{Albanian Frame of Reference}

Academical work and education on entrepreneurship are a recent development in Albania, due to the country's political and economic history. It was only after the 
1990's that entrepreneurial activity and business education began to play a role in the country's life and development. Foreign researchers and lecturers that have visited Albania in early ' 90 -s expressed their opinion by words "Albanian institutions of higher education are ill prepared to provide modern business education to the future leaders" [18]. Then, national and international operations and support were activated, most of them like those in other Eastern European countries [19]. The education system radically changed, and the market economy was developed. Lee \& Trimi point out that after the ' 90 -s "a massive dose of training and education in modern economics and management principles has greatly helped change the attitudes and behavior of the new generations of Albanians" [20].

\subsection{Albanian Universities for Entrepreneurship}

All economic, political, technological and educational changes have encouraged entrepreneurship in the country. However, there are few publications examining the entrepreneurial ecosystem and impact of entrepreneurship education on Albanian businesses. It is generally accepted that there is a gap between students' university education and entrepreneurial activity in the Albanian milieu [21-24].

Efforts to reduce this gap providing adequate suggestions on driving factors to entrepreneurial activity in universities are worthwhile. According to Graham's framework of the pillars of an entrepreneurial economy "good universities provide good entrepreneurship partners". This requires that universities set up programs responding to market skills and encourage applied research among faculty, as Asllani \& al recommend [21].

The factual situation of Albanian university programs is highlighted by few other authors [24-25]. University programs related to entrepreneurship were assessed [25] by conducting interviews in 27 of 41 public and non-public HEIs in Albania, as of 2016 [26]. The survey has revealed that graduate programs, such as Professional Masters or Master of Sciences, in most Albanian universities include classical courses on management, entrepreneurship and innovation. This is distinguished as a key factor to the successful entrepreneurial activity of students. From a narrow educational point of view, only a few universities (less than 15\%) consider entrepreneurship a set of competencies and skills that should be taught in an academic context. However, they view a broad range of courses, part of their programs, as imperative in order to become an entrepreneur [25].

Create an entrepreneur-friendly environment by developing business incubators and promote strategic alliances between entrepreneurial business and universities is another pillar to support reducing the abovementioned gap [21,27]. The presence and the extent of complementary activities are considered important constituents of the stimulatory "package" that universities could offer to encourage entrepreneurship in their environment [23-25]. The survey of 2016 [25] shows the experience with business incubators: about $45 \%$ of the institutions have explored the opportunity to be part of or build any structure that is expected to stimulate students' entrepreneurship within a five-year period. In 2019 Hach \& Trenkmann [27] argues that several universities have started to engage in entrepreneurship promotion, with some of them aspiring to open full-fledged incubators. However, none of them could establish one incubator within university up to now. Consequently, there is no proof of the impact this instrument might have. At the meantime, there are business incubators established and operating in Albania and many universities have formal agreements in place, but these partnerships mostly only exist in paper [27].

The role of university-industry collaboration has been further advanced with the triple helix model (university-industry-government) presented by Etzkowitz since the beginning of this century [28]. If they interact, their contribution to boost the flow of intellectual, financial, and human capital at any stage of development could increase significantly. In Albania university-industry collaboration is currently very low with both sides not recognizing potential to cooperate [27]. Increased efforts by all partners are recommended for improving these relations, in order that industry considers universities much more than only pools of graduates for filling company' vacancies.

\subsection{Purpose of the Study and Objectives}

Given the current situation, the purpose of our study is to promote relations between university education and entrepreneurship in Albanian higher education. Our opinion is that universities in general, especially the non-public ones in Albania, have access to resources that could potentially be used as a "starter kit" to encourage entrepreneurship. These resources can be activated through specific courses of action provided by European and global experience $[13,29-30]$.

Our study intends to encourage new business ideas toward their development, especially for the ventures that involve new products and processes, by stirring up the opportunities of the higher education ecosystem. Academia and practitioners accept that early evaluation of original business ideas and estimating their probability of success is difficult, even for university business incubators [4-5,30-31]. Attempts have been made to identify or develop semi-automatic judgement methods and means that can quickly and accurately, within certain limits, provide an estimation of the business idea' success $[10,30]$. Digital platforms are amongst these means. Platforms are now common to many organizations and provide ways in which people can engage with each other, 
suggest, comment, and focus on their innovation efforts.

The main goal of the study is to set the theoretical basis and to present the practical elements of a digital platform, which can be used as an instrument to assess and estimate the probable success of a business idea in the context of an academic institution.

Beyond the presentation of a simple, visible platform, we identify ways for universities to encourage entrepreneurship activities, even when financial dedicated resources are limited, as it's the case of most Albanian universities [23-24,27].

\section{Methods}

Our research is focused on the relationship between university education and entrepreneurship, considering both the organization (HEIs) and students as main actors. However, they are not the only stakeholders; the higher education ecosystem is comprised of many participants clearly proclaimed [17,27-28], whose contribution is also considered in our work.

The primary research question of this study is:

- what methods can we suggest for initiating and optimizing use of resources available in a university or business environment to the benefit of entrepreneurship?

To complement it, we have developed a secondary question:

- what opportunities does a digital platform offer to the preliminary assessment of the probability of success for a new business?

The methodology consists of following phases.

1. To achieve the main goal of this study, we adapted the method used to assess the probability of success for a business idea, into a digital platform or application, based on entrepreneurship literature and startup system university protocols [5,7,33-34].

The platform is designed in a systemic way, keeping in mind:

- the process a business idea goes through to become a venture. The application is conceived in a way that permits the applicant to face the key issues they should overcome when implementing the business idea. Starting a business requires clarification of many aspects related to the product/service being offered and the operation of the company. The step-by-step layout of the app forces the applicant to expound, including operations, marketing, finance and legal parts of the business plan. Distinguished publications and demonstrations on start-up procedures and company establishment have been consulted [12,33-36] for adapting a procedure suitable to our business environment.

- the possibility to revise an idea. As Ries demonstrates throughout his work [12], the business idea can change while it is being developed. The platform design permits the revision and modification of the initial idea. The concept of the product/service itself might change to fit customers' needs, the cost and required resources can be reduced in order to increase the competitiveness of the venture $[31,37]$. The possibility to go return to any previous step and make changes allows the applicant to improve on their idea and increase its chances of success.

- resources HEIs have access to. HEIs are gathering hubs for young people (sources of new ideas and forces of progress), academic staff (sources of scientific qualifications and higher levels of knowledge in their respective fields, often combined with practical industry experience), laboratory, IT and other infrastructure (resources for experimentation and testing of ideas), and are a point of contact with other stakeholders (source of financing opportunities, network effect, results dissemination).

Evaluating a business idea requires the expertise of qualified people in the areas of management, marketing, finance, and technical field, role that academic staff can perfectly play. The feasibility study and improved ideas have better chances to get funding. HEIs themselves might generate funds, especially from EU projects $[8,10,17,27]$ or orient towards crowdsourcing, bank support, and other sources [36].

2. The platform/ was created and the application was initially tested by a group of 30 students, whose suggestions and feedback were taken into consideration in constructing the final version.

3. The platform was launched online in 2017. The URL to the platform was accessible through our university's website and the company that worked on its development.

4. After further development, the platform has been fully functional since October 2019. As of February 2020, 87 application have been submitted, which have been examined and evaluated by the assessing team.

The theoretical framework and practical elements of the platform are discussed further in this paper.

\section{From Business Incubators to Digital Platforms - Discussion}

\subsection{Digital Market and Online Platforms}

The digital market in Albania is a relatively new concept. However, it has driven economic interest and is gradually becoming an important instrument to the country's European integration [38]. Technically, digital platforms are not new to the market, however they have 
been paid increasingly more attention during the last few years.

The European Commission provides the following definition: “'Online platform' refers to an undertaking operating in two (or multi)-sided markets, which uses the Internet to enable interactions between two or more distinct but interdependent groups of users so as to generate value for at least one of the groups" [39]. In our work we use this definition for online platforms, as a broad category of digital businesses, examples of which include search engines, online marketplaces, software platforms, the collaborative or sharing economy, and social networks. The attraction and participation of customers is one of the most noticeable challenges for online platforms, particularly those functioning as marketplaces [9,39]. Despite this challenge, the number of digital platforms is steadily growing.

It is not difficult to understand why businesses are attracted to digital platforms. They function as intermediaries bringing together various groups of users so that they can interact economically or socially. Researchers point out that platforms generate significant value as they facilitate transactions and exchanges between groups that would otherwise have difficulty to be carried out [39].

The openness of digital platforms makes them easily accessible, and they have low cost of entry for users, as well as low maintenance costs [16]. The platforms' development is supported by the network effect, as the researches show $[10,16,32]$.

These platforms have been newly adapted to be used in university environments for the development of new businesses and their successful performance has been observed in the USA, UK, Germany, and Northern European countries. Recently they are being used in countries such as Italy, Portugal, Spain, and Greece, all of which have in common a "problematic" economy and the need to find new growth resources [39].

Digital platforms established and/ or available in HEIs' websites have the greatest chances to support youth entrepreneurship, as they are closer to a high youth concentration and they are user-friendly to young people.

\subsection{The Customized Platform in A University Website}

The digital platform that we present as part of our work is a custom-made, authentic one, named Launchpad Albania (Fig. 1). It is set up as an instrument that allows the identification of creative elements, as well as the development of new ideas towards their transformation into entrepreneurial initiatives.

It is designed as an easy to use application and relatively simple in data processing. This platform allows for the collection, evaluation, analysis, and testing of students' new ideas, as individuals or groups.

The aim of platform is to collect as many ideas born in the university environment as possible, which can:

- be developed into new businesses by the students themselves (start-up),

- stimulate the development of existing businesses, owned by the students or their families,

- $\quad$ aid in the restructuring and reactivation of businesses currently in difficulties (re-start).

This digital platform records data entered from the applicants and goes through a ten-step procedure to provide several data sets as output. Input data allows for an estimation of the chances of success in case this business idea is implemented, and is accessible to mentors, investors, and angel investors. The platform is designed and built as a questionnaire that, if answered accurately, can provide experts with the necessary information to judge a venture. While there are still many steps between the calculation of a business idea's probability of success to its implementation, the platform can eliminate unclear, badly- structured, or economically disadvantageous ideas.

The steps used by the platform are as follows:

- Who is applying?

Personal data is required, if applying as an individual; relevant data, if applying as a juridical person and/or in case of group application.

- What is your idea?

This section is open for describing whatever the originator intends to achieve through their business idea. It has no limitations and permits a narrative, which can be further elaborated in the following steps.

- What is your potential customer's profile?

This can include information like age groups of potential customers and their evolution based on new demographic tendencies, evolution of this group's income in the economic context of the country where applied. The applicant is required to try turning their subjective idea into an objectively measurable one. Details on expected customer behavior might help defining the customer profile. This section is more easily completed if the applicant has education in or knowledge of marketing; education starts to make a difference [4].

- What product or service does your idea substitute?

No matter how innovative your idea is, something already exists in the market that more or less fulfills the same or similar need. After that, the applicant is required to describe what the suggested product/service offers more than existing options to the market (comfort, economy, enjoyment). Furthermore, what is the approximate amount that potential customers might spend for the new product/service.? Defining the direct and indirect competitors of their suggested product/service is also required from the applicant in this step. A good command of Porter' diamond theory, knowledge on cost 
accounting and economics, facilitates the applicant's work. Again, entrepreneurship education would play its primary role.

- How will this product/service idea be presented to others?

What is required from the applicant in this step generally includes: draft a system that makes all elements of your product (drawings, simulations, samples etc.) tangible, or provide a prototype, if it exists.

Draft a system that positions your product compared to other competitors. Running the 4P-s analysis for the product/service facilitates the completion of this section. The applicants can go further by including complementation and diversification analysis, if possible. The better their idea can be understood and described, the higher the chances it will be successful.

- Introduce the team that will implement this business idea.

Lee [20] notes that "Human resources are the key". The role of a team in completing successful work is well known. A detailed CV of the team members (if any) and presentation of their abilities to solve any problems that might arise during every development stage is required here. The applicant should describe the shared vision with other members and how they can work as a team, complementing and supporting each other. Management skills, earned by learning or practice, might become an advantage [7].

- What resources are needed to implement this business idea?

This section can start off by addressing financial issues: what funds are needed to implement this business idea? Mention the sum you are willing to invest for this business and what proportion of the funds needed does it make up. The applicant should estimate how much time is required to start this business. It is also expected from them to relate any unresolved problem before starting this business.
- Establishing a business plan for the venture, according to the following system.

The platform offers analytical spreadsheets to construct the business plan, describing specific actions, specific time periods, and specific costs. The applicant should mention which activities have unknown/ undefined costs for them, if any. Calculating the break-even point for the product/service is very helpful for further evaluation by experts. 'Time to market' for the product/ service is required as well.

- What development potential does the business idea have?

Several questions help the applicant to make the argument in this stage: Do you sell the product of work, or work time, and how do you capitalize? Do you sell the product alone, the patent, or a certain solution?

What is the market development potential for the product/ service, considering new consumption trends? [33]

- Last but not least: Are you willing to "dedicate your life" to this business, or is it a temporary desire? Is there anything else you want to include in this application?

Entrepreneurship is a risky career; the hero, apart from being intelligent and rational, also has to be passionate and emotional as evidenced by Souitaris et al. [14]. Entrepreneurial intentions of student-applicants if reinforced from their entrepreneurship education, will encourage them to stick to the idea, improve it and do their best to get funds. Whatever the case, Nabi et al. [40] argue that EE serves a valuable educational purpose; it leads to students becoming enlightened about entrepreneurship, and then re-focusing towards organizational careers, which appears to be a less risky and less challenging option. The applicant can also mention everything that seems crucial to them and is not included in earlier steps.

Launchpad Albania can be found at [41] for everyone that wants to apply. 

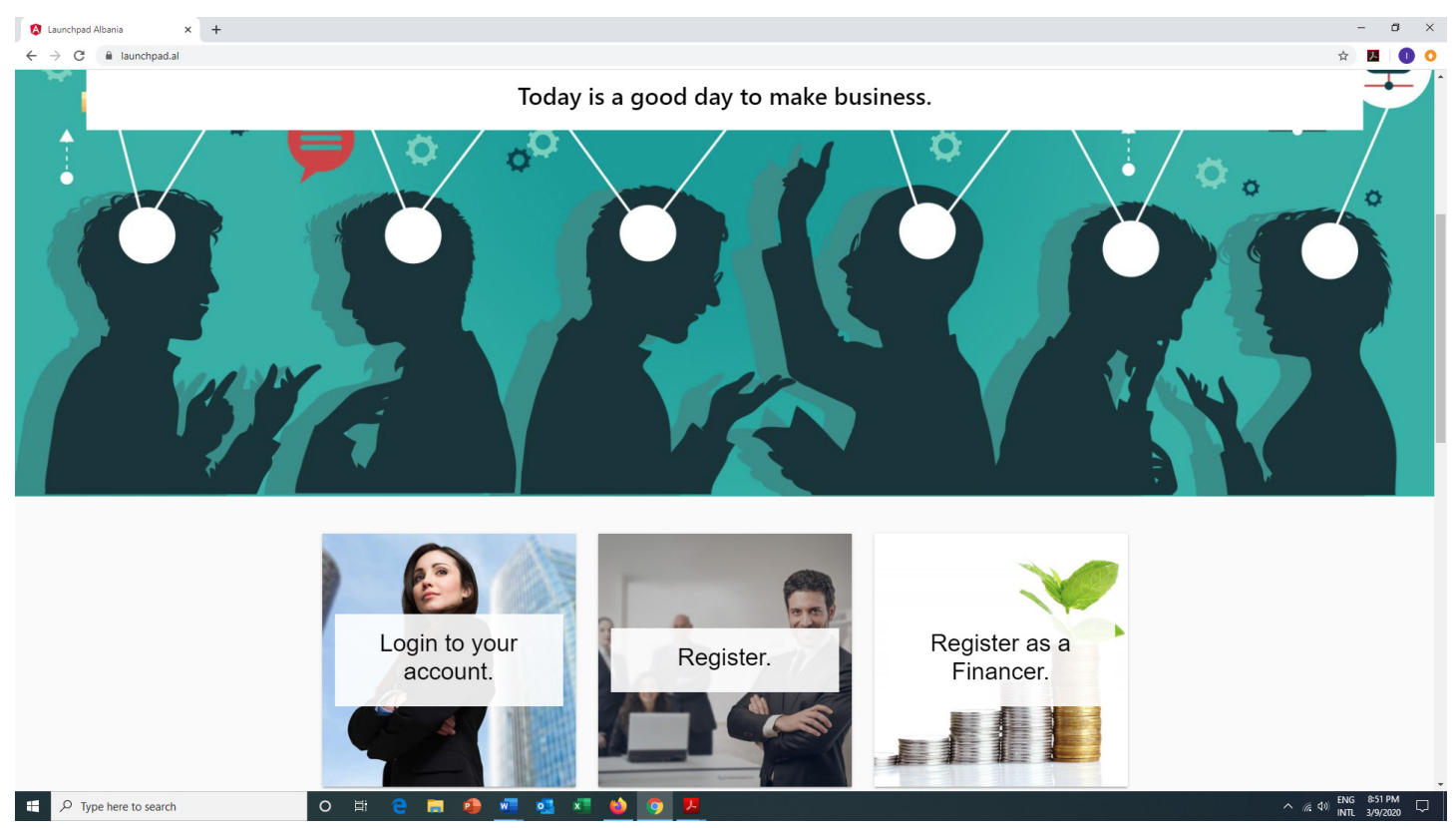

Figure 1. Launchpad Albania view

\subsection{Main Features of the Functional Platform}

The platform was designed to be used primarily by students, however without excluding other interested applicants; as such, it was posted on the websites of two institutions that agreed to collaborate with the authors.

We want to highlight that while the platform itself is handy, it would not be effective unless complemented by mentoring and evaluation elements.

Applicants type in responses to all questions in ten steps and submit the completed application. Afterwards, the complete application is sent to experts from several areas (marketing, management, finance, law, IT, engineering, as needed) who evaluate the business idea that is being proposed. They assess the probability of success and suggest financing options, when required. These experts are chosen or appointed from the HEIs hosting the platform and/or their partners.

The initial version of the platform was tested on a group of 30 students in economics, management and law bachelor and master's programs. Challenges and difficulties observed during the testing phase were addressed and led to changes in some of the steps in the final version, which are:

Step 5 - difficulty for product/service description and construction (reported by $30 \%$ of respondents). To facilitate comprehensive responses to this step, the option of attaching/uploading a drawing or demo (in the case of software) was added.

Step 8 - calculation of break-even point for the product/service was difficult for $80 \%$ of the respondents, due to lack of data and limited information on cost structure, mainly in new activities. To pass this hurdle, the option of interrupting the filling process and the possibility to consult with the experts was included. So, the evaluation team plays the role of mentor since during the application steps, helping to improve the idea and push towards implementation, or quit it, in case of low applicability.

The application was initially designed to be accessed by persons interested to developing their business ideas. During the test it was noticed that investors might be interested to have access in the "pool" of ideas, in order to fund them and turn in investments. This was complemented with a separate "window" for the financiers. It adds up to the role of the university for using its partnerships for fund raising and/or financing of business ideas generated by their students or other applicants within university platform.

The design of the platform, the algorithm it is based on, and the improvements after testing phase, permit to identify some of the platform's features:

- The platform works as a system that forces the applicants not only to present the idea, but especially to process it step by step, establishing a business plan. This enables an estimate of the success probability of the business idea and provides the experts with necessary information for further analysis of the idea.

- The platform contains "key questions", that help evaluate the feasibility of the idea, and enable avoiding mistakes and inaccuracy before moving on to the next step. Thus, relevant specialists can express opinions about the feasibility of the business idea, pushing it toward the final selection, up to the business plan appropriate for funding application and company start.

- The order in which information is required in the platform makes it rational. If the idea or its 
implementation plan is not clear, the algorithm does not allow the applicant to proceed to the next steps, thus submission of the proposal is stopped. It is either improved and goes up to the final step or rejected.

\subsection{The Users' Opinion and Further Steps}

The appraisal for the digital platform as an instrument well designed, user-friendly and beneficial, comes from the users.

The platform has recorded 87 applications. Three quarters of them are submitted by students. Unfortunately, 59 of the applications have not been completed. This means that the applicants have started with an idea but could not elaborate it sufficiently for deserving the evaluation and full support from the experts' team. For 12 more promising business ideas their applicants were asked to revise and improve presentations, through support of experts' team. The others were rejected.

2 of 28 finished applications are in the implementation stage, as there were investors found for them. The evaluation team, based on individuals' long experience in academia and business, and through university partnerships did support these applications to successfully acquire funding. 3 other applications are in the improvement process and trying to get funding from financial institutions. The others are on-hold for further decision-making.

The platform' users that have submitted the finished applications were asked to present their views. The main attributes of the platform highlighted are:

- it incites to expose problems not guessed before regarding the business idea, and pushes to solve them,

- it is during the process that applicant much better distinguish what they might do themselves and what others should help for,

- realistically grasp what economic and other risks they take,

- it is too challenging, but helpful to thoroughly understand what they will really do and hopefully achieve.

Timewise, it took them from weeks to months for completing the application but, in all cases, help was needed from specialists, within platform or outside it.

Up to this stage the platform has mainly used the resources of the individuals and those of the university involved. Meanwhile, there are options for making more useful the Launchpad Albania, or other similar platforms.

Increasing its visibility beyond the university' website requires the functioning of partnerships between university, industry and government. As generally accepted, the business opportunities are everywhere, if you are capable to evidence and catch them [30].

The platform can be considered as a 'digital brainstorming' application, that intends to use all resources every institution has or can gain through real experience exchange and partnership.

Sticking to the purpose of our study, we should also point out there are many facets of entrepreneurship education and ICT left out of this work. There are issues related to obstacles for entrepreneurship activity in the national context, the vulnerability of digital platforms in the cybersecurity context, the exposure of business information to collaborators, which can turn to competitors, as well as other topics we couldn't deal with in our study. They are either limitations of it, or otherwise named, issues for future research consideration.

\section{Conclusions}

The work presented in this paper intends to contribute in strengthening relations between university education and entrepreneurship.

Our study firstly highlights the effective ways for using the resources available in a university or business environment to the benefit of entrepreneurship. Business incubators and similar business-prompting structures located close to universities continuously increase the bond between entrepreneurship, entrepreneurial education, and general higher education, but it is time to find other ways to make this possible.

Secondly, it reveals the opportunities a digital platform can offer to assess the probability of success for new business ideas and encourage entrepreneurial activity. Digital platforms represent a new approach to create and implement novel business ideas and are highly accessible by young people. The basic layout of the applications, accessibility at any time and place, the vast amount of information that can be analytically assessed, and the fast processing time enable instant acquisition and objective analysis of the initial results of a business idea.

Digital platforms can give rise to business ideas, help to process them and enable simultaneous processing of the ideas by a number of interested parties. Due to the evident registration and recording of the submitting user, intellectual property of the initial idea is easily conserved.

Thirdly, it gives a practical contribution by displaying a live platform designed, established and tested with students, which can be broadly used.

Universities in Albania can and should use these recent development strategies to the benefit of their activities and the country's economy as well.

\section{Acknowledgements}

We thank two of our faculty members and colleagues for friendly-reviewing earlier drafts of the manuscript. We are very grateful to experts/reviewers for their appropriate 
and constructive suggestions to improve this template.

\section{REFERENCES}

[1] ETF/ CEDEFOP/ ILO, "Using labour market information Gide to anticipating and matching skills and jobs" Vol. 1, Publications Office of the European Union, 2016.

[2] European Commission, Working together for Europe's young people - A call to action on youth unemployment", Brussels, June 2013, online available: https://eur-lex.europa.eu/legal-content/EN/ALL/?uri=CEL EX:52013DC0447

[3] European Commission, Rethinking Education Strategy, Press Release, November 2012, online available: https://ec.europa.eu/commission/presscorner/detail/en/IP_1 2_1233

[4] C. E. Eesley, W. F. Miller, "Impact: Stanford University's Economic impact via innovation and entrepreneurship", Stanford University, USA, Oct. 2012.

[5] C. Lendner, "University technology transfer through university business incubators and how they help start-ups", Handbook of research on technoentrepreneurship, Edward Elgar Publishing 2009.

[6] 80/2015 Law on Higher education in the Republic of Albania, online available:https://euralius.eu/index.php/en/library/albanian-1 egislation/send/66-higher-education/168-law-on-higher-ed ucation-en.

[7] P. F. Drucker. Innovation and entrepreneurship, Practice and Principles, HarperCollins Publishers Inc., New York, 1984.

[8] Eurotech Universities Alliance. Nurturing the entrepreneurs of tomorrow, Brussels, 2015.

[9] OECD University-Industry Collaboration: New Evidence and Policy Options, OECD Publishing, Paris, https://doi.org/10.1787/e9c1e648-en, 2019

[10] OECD/ EU. Supporting Entrepreneurship and Innovation in Higher Education in Italy, OECD Skills Studies, OECD Publishing, Paris, https://doi.org/10.1787/43e88f48-en, 2019.

[11] J. Tidd. "Conjoint innovation: building a bridge between innovation and entrepreneurship", Intl. Journal of Innovation Management, Vol. 18, No.1, 2014, DOI: 10.1142/S1363919614500017.

[12] E. Ries. The Lean Startup. How today's entrepreneurs use continuous innovation to create radically successful businesses. Crown Business, New York, 2011.

[13] Online available: Start-up success stories, 2016, http://ec.europa.eu/programmes/horizon2020/

[14] V. Souitaris, S. Zerbinati, A. Al-Laham. Do entrepreneurship programmes raise entrepreneurial intention of science and engineering students? The effect of learning, inspiration and resources, Journal of Business Venturing, No.22, 2007, pp 566-591.
[15] C. Luethje, N. Franke, "Entrepreneurial intentions of business students: A benchmarking study" International Journal of Innovation and Technology, 1(3) 2004.

[16] A. Curth et al. Entrepreneurship Education: a road to success, Publication office of the European Union, Luxembourg, 2015

[17] ANVUR. "Le attività di Terza Missione: strategie, risorse ed impatto (Third Mission activities: strategies, resources and impact)", Biennial Report, Section 9, 2018. Online available:

http://www.anvur.it/download/rapporto-2018/ANVUR_Ra pporto Biennale 2018.pdf

[18] F. Luthans, S. M. Lee. "There Are Lessons to Be Learned as Albania Under-goes a Paradigm Shift", International Journal of Organizational Analysis, 2(1), 1994, pp 5-17.

[19] N. Pano, I. Gjika. "Contribution of USA in the development of Albanian education", Scientific Conference: US Policy in the Western Balkans, Mediterranean University of Albania, Tirana 2019.

[20] S. Lee, S. Trimi. "Developing Business Education Infrastructure in Eastern Europe: Albanian Experience", International Journal of Public Administration, Vol. 27, Nos. $11 \& 12$, 2004, pp. 869-881.

[21] A. Asllani, R. Becherer, Q. Theodhori. "Developing a sustainable economy through entrepreneurship: the case of Albania", South-Eastern Europe Journal of Economics, 2, 2014, pp 243-262.

[22] A. Bitzenis, E. Nito. "Obstacles to Entrepreneurship in a Transition Business Environment: the case of Albania", Journal of Small Business and Enterprise Development, 12(4), 2005, pp. 564-578.

[23] C. Cormier et al. Exploring Albania's entrepreneurial ecosystem, Publication of WPI and Yunus Social Business Balkan, 2016

[24] J.-G. Mora, C. Ferreira, J. Vidal, \& M.-J. Vieira. Higher education in Albania: developing third mission activities. Tertiary Education and Management, 21(1), 2015, pp 29 40

[25] I. Gjika, N. Pano, M. Shehaj. Managing innovation in university entrepreneurship. Third international scientific conference "Scientific challenges for sustainable development" International University of Struga, Macedonia, 2016.

[26] Quality Assurance Agency in Higher Education, Albania. Online available from: https://www.ascal.al/en/

[27] K. Hach, E. Trenkmann. Entrepreneurial \& Innovation Ecosystem in Albania, EU for Innovation, 2019. Online available:

http://euforinnovation.al/wp-content/uploads/2020/03/e-pu blication-of-the-regional-gap-analysis.pdf

[28] Stanford University (2016). Triple Helix IX. Retrieved February 27, 2016. Online available: http://www.triplehelixconference.org/th/9/the-triple-helix-c oncept.html

[29] J. Cenamor, V. Parida, J. Wincent. "How entrepreneurial SMEs compete throughdigital platforms: The roles of digital platform capability, network capability and 
ambidexterity”, Journal of Business Research, 100, 2019, pp 196-206.

[30] C. Barrow, "Incubators - a realist's guide to the world's new business accelerators", John Wiley and Sons Ltd., London, 2001.

[31] C. Corsi, D. di Berardino, "Assessing the business incubators' performance referring the local development in Italy", European Scientific Journal, Special edition Vol.1, September 2014.

[32] S. Nambisan, D. Siegel, M. Kenney. On open innovation, platforms, and entrepreneurship. Strategic Entrepreneurship Journal. 2018; 12:354-368. https://doi.org/10.1002/sej.1300

[33] N. M. Carter, W.B. Gartner, P. D. Reynolds, "Exploring start-up event sequences" Journal of Business Venturing, $11(3), 1996$.

[34] DEMOS Helisinki (n.d.), Demola Tampere An Open Innovation Platform of Co-Creation and Agile Experiments for Students, Businesses and Universities, Online available: https://www.demoshelsinki.fi/wpcontent/ uploads/2018/06/demola.pdf.

[35] A. Foglio. "Start up. La guida completa per chi vuole mettersi in proprio e creare da zero un'impresa di successo", Italy, 2015.

[36] G. Kawasaki. The art of the start 2.0: The time-tested, battle-hardened guide for anyone starting anything. Portfolio/Penguin, 2015.

[37] A. Biondi,."Sorry, but Italy is no startup paradise" AdEspresso June 13, 2014 Issue.

[38] N. Pano, I. Gjika. General impact of a single marketAlbania goes digital. IJSTR volume 5 - Issue 10, November 2016 edition, pp 197-200.

[39] House of Lords, Select Committee on European Union. Online platforms and the Digital Single Market, London, April 2016.

[40] G. Nabi, A. Walmsley, F. Linan, I. Akhtar \& C. Neame. Does entrepreneurship education in the first year of higher education develop entrepreneurial intentions? The role of learning and inspiration, Studies in Higher Education, 2016 DOI: 10.1080/03075079.2016.1177716.

[41] https://launchpad.al/ 